\title{
Population sinks in the Upper Florida Keys: the importance of demographic variation in population dynamics of the marine shrimp Stenopus hispidus
}

\author{
Brandon R. Chockley ${ }^{1,2, *}$, Colette M. St. Mary ${ }^{1}$, Craig W. Osenberg ${ }^{1}$ \\ ${ }^{1}$ Department of Zoology, 223 Bartram Hall, University of Florida, Gainesville, Florida 32611, USA \\ ${ }^{2}$ Fish Passage Center, 1827 NE 44th Avenue, Portland, Oregon 97213, USA
}

\begin{abstract}
The identification of sources and sinks in open populations is difficult and constrains our ability to predict population dynamics. This paper details factors that affect population size-structure of Stenopus hispidus Olivier, 1811, a popular marine ornamental, in the Upper Florida Keys and utilizes this information to identify large-scale (inshore-offshore) patterns of source-sink population structure. Shrimp were ca. 4 times more abundant at offshore sites compared to inshore sites. Larger reproductive shrimp dominated the inshore reefs in the Upper Florida Keys, while smaller, typically immature, shrimp dominated offshore reefs. Only $2.3 \%$ of settlement to artificial reefs occurred in the inshore region, while $97.7 \%$ occurred in offshore sites. Size-selective mortality was present but similar between the inshore and offshore reefs. Finally, growth declined with pre-molt size and was higher in the inshore than offshore reefs. These results indicated that the offshore reefs were likely dominated by smaller shrimp (at high density) due to higher settlement, lower growth rates and longer periods of susceptibility to size-selective mortality. To better understand the source-sink implications of our results, we developed a demographic model parameterized from our field estimates of size-specific molt frequency and mortality and region-specific (inshore or offshore) settlement and growth rates. We simulated settlement, mortality and growth both inshore and offshore and estimated reproductive output in the 2 regions. We found that shrimp in the inshore region exhibited higher levels of reproductive output than did shrimp in the offshore region. This suggests that the offshore region is acting as a population sink despite its higher local population size.
\end{abstract}

KEY WORDS: Demographic modeling $\cdot$ Marine reserves $\cdot$ Size-selective mortality $\cdot$ Source-sink theory $\cdot$ Stenopus hispidus

Resale or republication not permitted without written consent of the publisher

\section{INTRODUCTION}

Spatial variation in demography can strongly affect local subpopulation dynamics as well as aggregate population dynamics. Pulliam (1988) defined a sink habitat as a habitat within which reproduction is insufficient to balance local mortality, and the local population therefore persists only because it receives immigration from more productive source habitats. Pulliam developed this concept with reference to relatively closed populations in which most of the local production of offspring is retained at the local site. Application of this concept is complicated by the open nature of most marine populations because most of the local reproduction is dispersed to relatively distant sites via larval transport. Settlement into the local site is therefore decoupled from local production (Caley et al. 1996, but see Cowen et al. 2000, Warner et al. 2000, Swearer et al. 2002, Jones et al. 2005), and as a result, most local marine populations would be judged 'sinks' by Pulliam's definition. In open marine systems, a sink is better defined as a habitat that receives more settlers than it generates (i.e. where post-settlement survival and reproduction combined with larval mortality leads 
to $<1$ settler exported to surrounding subpopulations for each original settler into the local site). Identifying sources and sinks in marine systems therefore requires quantifying the relative importance of settlement vs. post-settlement processes, such as survival and reproduction as well as growth (because it indirectly affects size-specific survival and reproduction).

Knowing if habitats act as sources or sinks can inform management and conservation. For example, identifying sources can facilitate the design of marine reserves (Ogden 1997, Roberts 1998, Fogarty 1999, Crowder et al. 2000, Carr et al. 2003). Since population sizes reflect the level of recruitment to a habitat, as opposed to local offspring production, it is possible for sink habitats to support large populations and/or higher densities. Therefore, it has been proposed that targeting and protecting habitats that support larger populations or high densities, or receive higher settlement, may not necessarily be the best option (van Horne 1983, Roberts 1998). For example, Crowder et al. (2000) developed a model that suggested that the exclusive protection of sink habitats could result in an overall loss of fish populations, particularly if fishing efforts were increased outside the reserve. However, when reserves were placed at random or exclusively in source habitats, fish populations generally increased, regardless of whether displacement of fishing effort occurred. These results are contrary to the notion that any and all protected areas will be beneficial to marine populations and thus warrant empirical investigations into source-sink theory with respect to marine populations.

Spatial (and/or temporal) variation in benthic demographic processes is critical to source-sink dynamics. Furthermore, these same processes should affect population size-structure, and therefore the study of size-structure might provide a means to better understand source-sink processes. Although spatial variation in size-structure is well documented in marine invertebrates, many of these studies focus on the effect of a single demographic process, such as settlement rates (Minchinton \& Scheibling 1991) or postsettlement mortality and growth (Gust et al. 2002, Ruttenberg et al. 2005). Concentrating on a single process alone may overlook more important processes, ignore their interactions or misinterpret patterns due to associated changes in the understudied processes (e.g. Ólafsson et al. 1994, Caley et al. 1996, Hunt \& Scheibling 1997, Rochette \& Dill 2000).

For example, settlement, mortality and growth can interact to affect the size-structure and dynamics of a population. In fish it has been hypothesized that lower growth rates, coupled with size-selective mortality, could prolong periods of vulnerability to predators (Leggett \& DeBlois 1994), increase mortality (Werner et al. 1983) and/or increase the amount of time it takes to reach a size-refugium and sexual maturity (Werner et al. 1983, Miller et al. 1988, Bailey \& Houde 1989). Thus, differential growth between 2 habitats, whatever its cause, and the presence of size-selective mortality can give rise to spatial variation in size-structure, mortality and reproductive rates and therefore contribute to source and sink dynamics.

The overall objectives of the current study were to (1) compare the abundance and size-structure of subpopulations of the cleaner shrimp Stenopus hispidus among different reefs and regions in the Upper Florida Keys and (2) examine the mechanisms that produce spatial variation in population size and size-structure. In particular, we examine (i) settlement, (ii) post-settlement mortality and (iii) growth rates of shrimp inhabiting inshore and offshore reefs. With these data, we (3) developed a demographic model to evaluate the hypothesis that offshore reefs are a sink, despite the higher abundance of shrimp that occur there.

\section{EMPIRICAL STUDIES: MATERIALS AND METHODS}

Study species. Stenopus hispidus is a reef-associated cleaner shrimp (Decapoda: Stenopodidae) with a worldwide distribution. Adults occur in crevices or overhangs in reefs at depths ranging from $<1$ to $210 \mathrm{~m}$ and are extremely limited in post-settlement dispersal $\left(<1 \mathrm{~m}^{2}\right.$; Chockley \& St. Mary 2003) with males exhibiting territorial behavior (Limbaugh et al. 1961, Stolen 1964, Young 1979, Fletcher et al. 1995). Adults are often found in reproductive pairs (Johnson 1969, Young 1979), possibly formed as juveniles (Limbaugh et al. 1961). After each molt, the female typically mates with her long-term mate, and a mass of blue-green eggs is deposited on the swimmerets (Zhang et al. 1998). Hatching occurs within ca. $16 \mathrm{~d}$ of spawning (Young 1979). Larval duration is variable (17 to $30 \mathrm{wk}$ ) with larvae capable of delaying metamorphosis when suitable habitat is unavailable (Fletcher et al. 1995). Settlement cues are unknown.

Population structure. During the summers of 2001 and 2002 (May to August), we conducted surveys of both inshore and offshore reefs in the Upper Florida Keys (Table 1) to quantify spatial and temporal variation in Stenopus hispidus abundance, size-structure and reproductive output. Inshore reefs were located 1 to $2 \mathrm{~km}$ from shore at a depth of 3 to $6 \mathrm{~m}$, whereas offshore reefs were 6 to $7 \mathrm{~km}$ offshore and were either shoreward of the reef crest at depths of 6 to $10 \mathrm{~m}$ ('shallow') or on the reef slope at depths of 14 to $16 \mathrm{~m}$ ('deep'). The shallow offshore sites were not sampled in 2001; we added them to the present study in 2002 to evaluate if the inshore-offshore patterns were primar- 
Table 1. Details of reefs used in population size-structure study. Reef codes (in parentheses) correspond to those used in Fig. 1

\begin{tabular}{|c|c|c|c|c|c|}
\hline $\begin{array}{l}\text { Region } \\
\text { and site }\end{array}$ & Depth (m) & $\begin{array}{c}\text { Distance from } \\
\text { shore }(\mathrm{km})\end{array}$ & Reef type & Coordinates & $\begin{array}{c}\text { Year(s) } \\
\text { surveyed }\end{array}$ \\
\hline \multicolumn{6}{|l|}{ Inshore } \\
\hline Rock $1(\mathrm{R} 1)^{\mathrm{a}}$ & 3.05 & 1.63 & Patch & $24^{\circ} 56.548^{\prime} \mathrm{N}, 80^{\circ} 33.666^{\prime} \mathrm{W}$ & 2001 and 2002 \\
\hline Rock $2(\mathrm{R} 2)^{\mathrm{a}}$ & 3.66 & 1.60 & Patch & $24^{\circ} 56.991^{\prime} \mathrm{N}, 80^{\circ} 33.157^{\prime} \mathrm{W}$ & 2001 and 2002 \\
\hline Rock 3 (R3) ${ }^{a}$ & 5.79 & 2.04 & Patch & $24^{\circ} 57.258^{\prime} \mathrm{N}, 80^{\circ} 32.774^{\prime} \mathrm{W}$ & 2001 and 2002 \\
\hline Shrimp Rock 1 (SR1) & 3.66 & 1.47 & Patch & $24^{\circ} 56.909^{\prime} \mathrm{N}, 80^{\circ} 33.251^{\prime} \mathrm{W}$ & 2002 \\
\hline \multicolumn{6}{|l|}{ Offshore } \\
\hline Alligator Deep (AD) & 16.2 & 7.23 & Contiguous & $24^{\circ} 50.526^{\prime} \mathrm{N}, 80^{\circ} 37.464^{\prime} \mathrm{W}$ & 2002 \\
\hline Alligator Shallow (AS) & 7.62 & 6.74 & Contiguous & $24^{\circ} 51.221^{\prime} \mathrm{N}, 80^{\circ} 36.823^{\prime} \mathrm{W}$ & 2002 \\
\hline Davis Deep (DD) ${ }^{\mathrm{a}}$ & 14.6 & 7.60 & Contiguous & $24^{\circ} 55.461^{\prime} \mathrm{N}, 80^{\circ} 30.019^{\prime} \mathrm{W}$ & 2001 and 2002 \\
\hline Davis Shallow (DS) & 9.45 & 7.15 & Contiguous & $24^{\circ} 55.029^{\prime} \mathrm{N}, 80^{\circ} 30.614^{\prime} \mathrm{W}$ & 2002 \\
\hline Crocker Deep (CD) ${ }^{\mathrm{a}}$ & 14.6 & 7.02 & Contiguous & $24^{\circ} 54.279^{\prime} \mathrm{N}, 80^{\circ} 31.681^{\prime} \mathrm{W}$ & 2001 and 2002 \\
\hline Crocker Shallow (CS) & 6.71 & 6.69 & Contiguous and patch & $24^{\circ} 54.454^{\prime} \mathrm{N}, 80^{\circ} 31.672^{\prime} \mathrm{W}$ & 2002 \\
\hline
\end{tabular}

ily due to effects of depth or distance from shore. During each survey, we thoroughly searched each reef and surrounding rocks for $S$. hispidus. Every shrimp encountered was collected by divers using hand nets, measured (total length [TL] in $\mathrm{mm}$ ), sexed underwater (male, female and immature) and released at the point of collection. Sex was assigned using criteria outlined in Chockley \& St. Mary (2003).

We evaluated the effects of region (inshore or offshore), site (i.e. reef), years and their interactions on shrimp TL (log-transformed) for reefs that were sampled in both years using a nested-ANOVA model with site nested within region. In the case of a significant year effect in this analysis, separate nested-ANOVAs were run for each year, testing for region and site effects, again with site nested within region. All sites for a given year (5 sites in 2001 and 10 in 2002) were included in these separate analyses, including those that were not surveyed both years. When a significant site effect was found, post-hoc comparisons were conducted to determine which sites differed.

Reproductive output. We estimated regional reproductive output (i.e. total no. of eggs produced per region) for each year using the size of each gravid female and the relationship between female size $\left(L_{\mathrm{f}}\right)$ and egg number $\left(N_{\mathrm{e}}\right)$, given in Chockley \& St. Mary (2003):

$$
\log _{10}\left(N_{\mathrm{e}}\right)=-4.21+4.48 \log _{10}\left(L_{\mathrm{f}}\right)
$$

Larval settlement. To quantify spatial variation in settlement of Stenopus hispidus in the Upper Florida Keys, we used artificial reefs constructed from small limestone boulders taken from a single quarry in Miami, Florida. Reefs were deployed within a few days of one another in June 2001 and were ca. $1 \mathrm{~m}^{2}$ in basal area. Each region (inshore vs. offshore) consisted of 2 transects of 5 artificial reefs running perpendicular to shore. Reefs within transects were isolated from their nearest reef neighbor by 5 to $270 \mathrm{~m}$, and the 2 transects within a region were ca. $1 \mathrm{~km}$ apart. In the summer of 2002 (May to July), we conducted 10 weekly surveys and collections from each artificial reef. Collections consisted of removing all fishes and invertebrates using clove oil (an anesthetic) and preserving them in $95 \%$ EtOH for later identification and measurement. The largest shrimp collected was $20.8 \mathrm{~mm}$ TL, which, based on the size of the smallest shrimp collected, observed growth rates and the weekly sampling scheme, was small enough to have settled directly to the artificial reefs. Thus, we assumed that all of the shrimp settled to the reefs instead of migrating from nearby reefs.

Counts were square-root-transformed and analyzed with a repeated-measures ANOVA to test for the effect of region (inshore or offshore), transect (nested within region) and week (the repeated factor) on the number of settlers.

Post-settlement mortality. To quantify spatial and temporal variation in post-settlement mortality rates of Stenopus hispidus, we conducted a tagging study at 3 inshore and 2 offshore reefs during the summers of 2001 (July to August) and 2002 (May to July) (Table 1). Holes containing shrimp were located, mapped and marked. Shrimp from these holes were tagged (following methods in Chockley \& St. Mary 2003), measured (TL in mm), sexed and released to their original holes. To keep track of individuals, a total of 6 colors was used, and shrimp marked with the same color were always further apart than their expected home range (ca. $1 \mathrm{~m}$ ) (Limbaugh et al. 1961, Stolen 1964, Young 1979). We then conducted weekly surveys of each reef and (1) recorded presence/absence of previously tagged shrimp, (2) tagged, measured and sexed any newly encountered shrimp and (3) in 2001 measured the distance moved (if an individual moved from its original site). 
Since each shrimp was individually recognizable, the time to disappearance of an individual was known. Because of the limited post-settlement movement reported for this species (Chockley \& St. Mary 2003), we assumed that disappearances from the study area were the result of mortality rather than movement. Times to disappearance were analyzed using survivorship analysis (Generalized Gamma Model), which allows for the estimation of the effects of covariates on shrimp mortality (Barbeau et al. 1994, Allison 1995). To eliminate tagging-induced mortality from estimates of natural mortality, we excluded from the analysis all shrimp that died within the first week of tagging. Covariates considered in the full survival analysis included shrimp size (TL in $\mathrm{mm}$ ), region (inshore or offshore) and site (5 sites used in the present study). The full model was simplified by excluding covariates whose effects were non-significant. Estimates from the reduced statistical model were used to parameterize the demographic model (details further discussed in 'Materials and methods: Modeling exercises').

Growth. In 2002 the left exopod of each shrimp's uropod was clipped when first tagged (and upon recapture if it had molted and grown between recaptures). The clipped portion is replaced only after molting and the time between molts exceeds $7 \mathrm{~d}$ (Chockley \& St. Mary 2003). Thus, we estimated growth for each shrimp that molted as the difference in the mean premolt and post-molt lengths. We used 2-way ANCOVA to test for the effects of region (inshore or offshore), mean pre-molt length and their interaction on mean growth increment. To estimate parameters in our model (see 'Materials and methods: Modeling exercises'), we also conducted separate linear regressions for the inshore and offshore reefs.

Because the inshore and offshore reefs used in the present growth study differed in depth, and because temperature is generally negatively correlated with depth (Lee et al. 1992) and can affect crustacean growth (reviewed in Hartnoll 2001), we measured bottom temperature at each of the reefs repeatedly throughout the summer of 2002. Mean temperatures were calculated for each region (inshore or offshore) and compared with a $t$-test.

\section{EMPIRICAL STUDIES: RESULTS}

\section{Population structure}

In 2001 we collected, measured and sexed a total of 111 shrimp. Of these, 30 were found inshore while the remaining 81 were found offshore. Of the total 236 shrimp surveyed in 2002, 46 were found inshore, while the remaining 190 were found offshore. Therefore, when both years were combined, only $21.9 \%$ of the surveyed shrimp were found in the inshore region, while the vast majority ( $78.1 \%$ ) were found offshore.

Overall, shrimp from inshore reefs were ca. $18 \mathrm{~mm}$ larger than those from offshore reefs (Fig. 1; nested ANOVA: $F_{1,251}=317.6, \mathrm{p}<0.0001$ ) and shrimp collected in 2001 were $5 \mathrm{~mm}$ larger than those collected in 2002 (nested ANOVA: $F_{1,251}=13.90, \mathrm{p}=0.0002$ ). There was no effect of site (within region) or any interactions among factors (nested ANOVA: all $F<1.94$, all p > 0.13; Fig. 1).

Due to the significant year effect and differences in the sites sampled in 2001 vs. 2002, each year was analyzed separately. In both years, the inshore and offshore regions differed significantly in shrimp body size

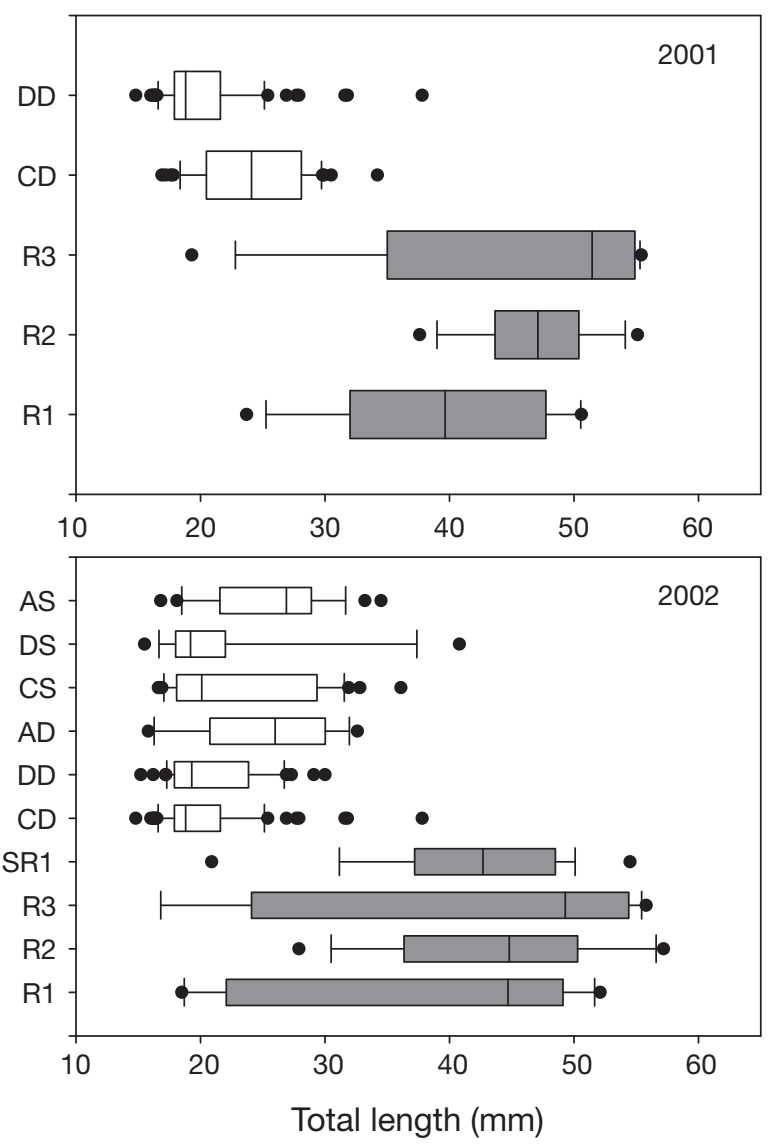

Fig. 1. Stenopus hispidus. Box plots of total length $(\mathrm{mm})$ for all reefs surveyed in 2001 and 2002. Shaded boxes: inshore reefs; unshaded boxes: offshore reefs. Reef abbreviations as in Table 1. Boxes contain $50 \%$ of the sample values (1st sample quartile through 3 rd sample quartile). The 2 whiskers extend within a range of 1.5 times the interquartile range. Dots represent outliers. The vertical line in each box represents the median of each sample. Sample sizes in 2001: $C D, n=43 ; \mathrm{DD}, \mathrm{n}=38$; $\mathrm{R} 2, \mathrm{n}=12 ; \mathrm{R} 1, \mathrm{n}=10 ; \mathrm{R} 3, \mathrm{n}=8$; in 2002: $\mathrm{CD}, \mathrm{n}=74 ; \mathrm{CS}, \mathrm{n}=29$; $\mathrm{DD}, \mathrm{n}=44 ; \mathrm{DS}, \mathrm{n}=14 ; \mathrm{AD}, \mathrm{n}=9 ; \mathrm{AS}, \mathrm{n}=20 ; \mathrm{R} 1, \mathrm{n}=9$; $\mathrm{R} 3, \mathrm{n}=14 ; \mathrm{SR} 1, \mathrm{n}=14 ; \mathrm{R} 2, \mathrm{n}=9$ 
(nested ANOVA: 2001, $F_{1,106}=146.97, \mathrm{p}<0.0001 ; 2002$, $\left.F_{1,226}=178.29, \mathrm{p}<0.0001\right)$. In 2001, there was no significant variation among reefs within a region (nested ANOVA: $F_{3,106}=1.55, \mathrm{p}=0.21$ ), although there was significant variation within regions in 2002, when more reefs were sampled $\left(F_{8,226}=2.97, \mathrm{p}=0.0035\right.$; Fig. 1$)$. This heterogeneity was primarily associated with the offshore region, with shrimp from Alligator Reef being larger than those from Crocker or Davis (Fig. 1). In contrast to this heterogeneity offshore, there were no significant differences in shrimp body size among the 4 inshore reefs surveyed in 2002 ( $p>0.115$ for all comparisons). Among the 3 offshore areas that had both shallow and deep sites surveyed in 2002, only Crocker exhibited a significant difference in mean shrimp size between the 2 depths ( $p=0.039$ ), and this difference was only $2.3 \mathrm{~mm}$ (Fig. 1). Thus, the variation in size seems more closely tied to the inshore-offshore gradient than a depth gradient per se.

\section{Reproductive output}

In 2001, the total reproductive output in the inshore region was ca. 12.6 times greater than that offshore (inshore: 25312 eggs, offshore: 2010 eggs). In 2002, there was a similar discrepancy in production in the inshore and offshore regions, with the inshore region producing 12.0 times more eggs than the offshore region (inshore: 29996 eggs, offshore: 2501 eggs).

\section{Larval settlement}

In 10 wk of sampling only 1 shrimp was collected from the inshore artificial reefs, whereas 43 were collected offshore (repeated measures ANOVA: $F_{1,2}=$ 64.08, $\mathrm{p}=0.0152$ ), although the number of settlers was unaffected by week or array within region $(F<1.81$, $\mathrm{p}>0.1$, for both tests; Fig. 2). The average size \pm SE of all the settlers collected was $17.38 \pm 0.19 \mathrm{~mm} \mathrm{TL}$ (range: 14.0 to $20.8 \mathrm{~mm}$ ).

\section{Post-settlement mortality}

There was no significant effect of region on postsettlement mortality (Wald's Chi-square: $\chi^{2}=1.29$, $\mathrm{df}=1, \mathrm{p}=0.26$ ). In the reduced model (with region removed), survival increased with shrimp size (Fig. 3; Wald's Chi-square: $\chi^{2}=8.34$, df $=1, \mathrm{p}=0.0039$ ) and varied among sites (Wald's Chi-square: $\chi^{2}=33.1$, df $=$ $5, \mathrm{p}<0.0001)$. In particular, shrimp at Crocker Deep and Rock 1 both had lower survival compared to the mean $\left(\beta_{\mathrm{CD}} \pm \mathrm{SE}=-0.46 \pm 0.15, \beta_{\mathrm{R} 1} \pm \mathrm{SE}=-0.73 \pm 0.25\right)$;

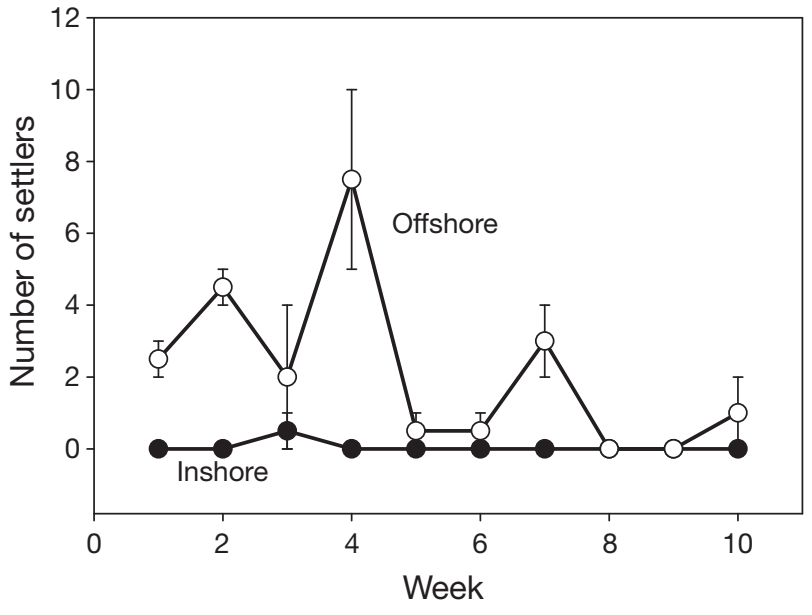

Fig. 2. Stenopus hispidus. Mean \pm SE number of settlers to inshore and offshore artificial reefs in each of 10 weekly surveys

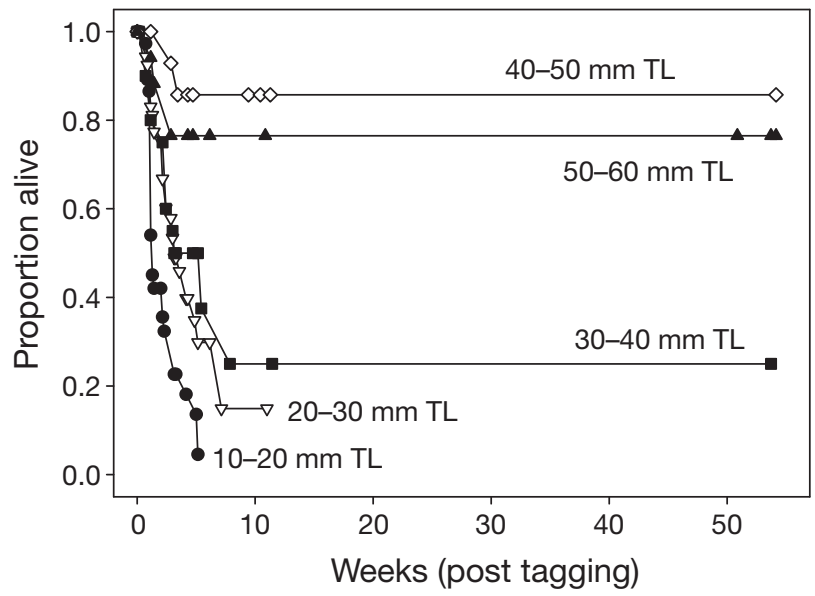

Fig. 3. Stenopus hispidus. Survivorship curves of 5 sizeclasses for 2001 and 2002 and all reefs combined. 10 to $20 \mathrm{~mm}$ individuals had survivorships that were significantly different from those of 20 to $30 \mathrm{~mm}$ and 30 to $40 \mathrm{~mm}$, which had different survivorship than those of 40 to $50 \mathrm{~mm}$ and 50 to $60 \mathrm{~mm}$ TL. Sample sizes were: 50 to $60 \mathrm{~mm}, \mathrm{n}=17 ; 40$ to $50 \mathrm{~mm}, \mathrm{n}=$ 15 ; 30 to $40 \mathrm{~mm}, \mathrm{n}=21 ; 20$ to $30 \mathrm{~mm}, \mathrm{n}=54 ; 10$ to $20 \mathrm{~mm}, \mathrm{n}=$ 40. This figure is an adaptation from Fig. 2 in Chockley \& St. Mary (2003) and is being published with permission from the Journal of Crustacean Biology

no other site had survival that differed from the overall mean.

\section{Growth}

Both shrimp size and region had significant effects on mean growth increment (Fig. 4; ANCOVA: shrimp size, $F_{1,51}=8.17, \mathrm{p}=0.006$; region, $\left.F_{1,51}=7.85, \mathrm{p}=0.007\right)$, 


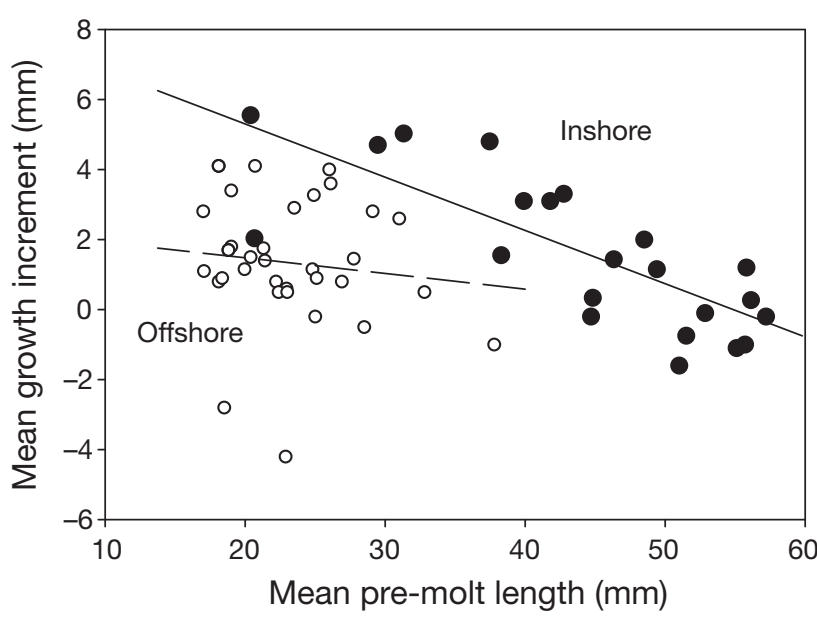

Fig. 4. Stenopus hispidus. Linear regression of mean growth increment on mean pre-molt length for inshore (ब) and offshore (O) populations. Sample sizes are inshore, $\mathrm{n}=22$; offshore, $\mathrm{n}=33$. Parameter estimates for regression lines are given in Table 2

and there was no significant interaction (ANCOVA: interaction, $F_{1,51}=2.33, \mathrm{p}=0.133$ ). In general, mean growth increment decreased with shrimp size and was significantly higher inshore than offshore (least-square means \pm SE: $3.48 \pm 0.55$ [inshore] versus $0.95 \pm 0.59 \mathrm{~mm}$ [offshore]). With each region being analyzed separately, there was a significant negative relationship between growth increment and pre-molt length on the inshore reefs (linear regression: $F_{1,20}=30.71, \mathrm{p}<0.0001$; Table 2 ; Fig. 4$)$, but not the offshore reefs $\left(F_{1,31}=0.48\right.$, $\mathrm{p}=0.49$; Table 2 ; Fig. 4 ). The mean bottom temperature \pm SE was just over 1 degree warmer at the inshore versus offshore reefs $\left(27.6 \pm 0.3^{\circ} \mathrm{C}\right.$ versus $26.5 \pm 0.3^{\circ} \mathrm{C}_{i} t_{27}=$ $2.77, \mathrm{p}=0.010$ )

\section{MODELING EXERCISES: MATERIALS AND METHODS}

We developed a simulation model and parameterized it with our field data to evaluate the implications of variation in vital rates between inshore and offshore

Table 2. Stenopus hispidus. Parameter estimates and test statistics from linear regression models to estimate the growth increment for shrimp from the inshore and offshore reefs, as in Eq. (3). Graphical representations for these parameter estimates can be seen in Fig. 4

\begin{tabular}{|c|c|c|c|c|c|c|}
\hline \multirow{2}{*}{ Region } & \multicolumn{2}{|c|}{ — Parameter estimates — } & \multirow[b]{2}{*}{$F$-value } & \multicolumn{2}{|c|}{ Test statistics } & \multirow[b]{2}{*}{$r^{2}$} \\
\hline & $j \pm \mathrm{SE}$ & $k \pm \mathrm{SE}$ & & $\mathrm{df}_{\mathrm{n}, \mathrm{d}}$ & $\mathrm{p}>F$ & \\
\hline Inshore & $8.32 \pm 1.25$ & $-0.153 \pm 0.027$ & 30.71 & 1,20 & $<0.0001$ & 0.61 \\
\hline Offshore & $2.42 \pm 1.60$ & $-0.047 \pm 0.067$ & 0.48 & 1,31 & 0.4942 & 0.02 \\
\hline
\end{tabular}

regions. Our model had 2 components, one that described the growth process and one that described demographic rates (settlement, survival and reproduction).

Growth model. We developed a stochastic growth model (see Chen \& Kennelly 1999, Chockley \& St. Mary 2003) that simulated individual growth trajectories based on 3 life history steps: (1) a size at settlement, $L_{1}$, (2) weekly molt probability, $P_{\mathrm{m}}$, and (3) growth (conditional on molting and pre-molt size). The growth process (steps 2 to 3) was repeated in each region for 20 shrimp for 100 wk to obtain a distribution of growth curves for each region. Mean size \pm SD at age was estimated from the distribution of growth curves for each region. Note that these growth trajectories are independent of size-selective mortality (which we incorporate in a separate step, see 'Demographic model').

The distribution of settler sizes was based on estimates from Chockley \& St. Mary (2003), with a mean \pm SD size at settlement of $16.88 \pm 0.89 \mathrm{~mm}$ (range: 14.8 to $18.4 \mathrm{~mm}$ ). The estimate for $P_{\mathrm{m}}$ varied with shrimp size and was based on data presented in Chockley \& St. Mary (2003) as:

$$
P_{\mathrm{m}}=1-\frac{\Gamma_{\mathrm{m}}\left(\delta_{\mathrm{m}}^{-2}, \delta_{\mathrm{m}}^{-2}\left(\sigma_{\mathrm{m}} \cdot \mathrm{e}^{\left(-a_{\mathrm{m}}+b_{\mathrm{m}} L\right)} \cdot t_{\mathrm{m}}\right)^{\delta_{\mathrm{m}}}\right)}{\Gamma_{\mathrm{m}}\left(\delta_{\mathrm{m}}^{-2}\right)}
$$

with the incomplete gamma function in the numerator and the gamma function in the denominator. The parameters $\delta_{\mathrm{m}}$ and $\sigma_{\mathrm{m}}$ represent the shape and scale parameters in the model, respectively, and $a_{\mathrm{m}}$ and $b_{\mathrm{m}}$ characterize the effect of the covariate, shrimp size $(L)$. Estimates for the fitted parameters, $\delta_{\mathrm{m}}, \sigma_{\mathrm{m}}, a_{\mathrm{m}}$, and $b_{\mathrm{m}}$ $\left( \pm\right.$ SE), were: $\delta_{\mathrm{m}}=-0.6007 \pm 0.4302, \sigma_{\mathrm{m}}=0.4044 \pm$ $0.0529, a_{\mathrm{m}}=-0.5798 \pm 0.2122$ and $b_{\mathrm{m}}=0.0350 \pm 0.0052$ (Chockley \& St. Mary 2003).

Estimated growth increments for given pre-molt sizes were based on linear regression analyses conducted to describe the relationship between mean pre-molt length and mean growth increment for each region (Table 2; Fig. 4). Although there was no significant effect of length on growth increment for offshore shrimp $(p=0.49)$, this linear regression model is our best estimate of a relationship that is generally found in other crustaceans (e.g. Tremblay \& Eagles 1997, Chen \& Kennelly 1999, Comeau \& Savoie 2001) and is clear in our inshore region. Therefore, the equations for the estimated growth increment for each region were:

$$
\Delta L_{\mathrm{i}}=j_{\mathrm{i}}+k_{\mathrm{i}} L+\varepsilon_{\mathrm{i}}
$$

where $\Delta L_{\mathrm{i}}$ is the region-specific growth increment following a molt, $L$ is the pre-molt size, $j_{\mathrm{i}}$ and $k_{\mathrm{i}}$ are region- 
specific parameter estimates provided by the linear regression models (as in Table 2) and $\varepsilon_{\mathrm{i}}$ is an error term. To provide estimates of variation in growth $(\varepsilon$ in Eq. 3), separate SD (inshore deviation $=1.35$, offshore deviation $=1.82$ ) from the predicted growth increment for each region were estimated and incorporated into the growth model.

Demographic model. We incorporated estimates of weekly size-specific mortality into our regional growth model by assigning 50000 settlers an initial size (based on the distribution of sizes at settlement from Chockley \& St. Mary 2003), a settlement wk (selected at random, between 0 and 200), a sex $\left(P_{\text {male }}=0.5\right)$ and a settlement region (with $P_{\text {offshore }}=0.977$ to reflect the observed differences in settlement rates) (Fig. 2).

After this initial assignment, settlers either survived or died based on an estimated weekly size-specific survival $\left(P_{\mathrm{s}}\right)$. As mentioned above, under a simplified survivorship analysis, we found that survival increased with shrimp size and varied among sites (see 'Results: Empirical studies'). However, since the 2 sites that exhibited lower survival (Crocker Deep and Rock 1) were split among the inshore and offshore regions and their departure from the overall mean was small, we ignored this site-specific variation in the survival portion of our demographic model. Therefore, the weekly probability of survival $\left(P_{\mathrm{s}}\right)$ was estimated as:

$$
P_{\mathrm{s}}=1-\frac{\Gamma_{\mathrm{s}}\left(\delta_{\mathrm{s}}^{-2}, \delta_{\mathrm{s}}^{-2}\left(\sigma_{\mathrm{s}} \cdot \mathrm{e}_{\mathrm{s}}^{\left(-a_{\mathrm{s}}+b_{\mathrm{s}} L\right)} \cdot t_{\mathrm{s}}\right)^{\delta_{\mathrm{s}}}\right)}{\Gamma_{\mathrm{s}}\left(\delta_{\mathrm{s}}^{-2}\right)}
$$

with the incomplete gamma function in the numerator and the gamma function in the denominator. Under this simplified model, the shape $\left(\delta_{\mathrm{s}}\right)$ and scale $\left(\sigma_{\mathrm{s}}\right)$ parameter estimates $( \pm \mathrm{SE})$ were $-1.064 \pm 0.416$ and $0.944 \pm$ 0.104 , respectively. In addition, the parameters $a_{\mathrm{s}}$ and $b_{\mathrm{s}}$, which estimate the effect of the covariate (i.e. shrimp size, L) on survivorship, were $-0.186 \pm 0.216$ and $0.037 \pm 0.010$, respectively.

Those individuals that survived molted at the estimated weekly size-specific molting probability (Eq. 2). Individuals that molted grew at the estimated regionand size-specific growth rates (Eq. 3; Table 2). This process was repeated for each individual until death occurred. The week of death was recorded for each shrimp.

To establish a range of possible reproductive outputs for the 2 regions, we considered 3 reproduction scenarios: (1) 'no pairing' (i.e. mates were not limiting and all mature females reproduced), (2) 'region-specific pairing' (i.e. female reproduction was limited only by the availability of a mate in the same region) and (3) 'sitespecific pairing' (i.e. female reproduction was limited by the availability of a mate in the same site). The 'sitespecific pairing' scenario was developed to explore possible limitations in reproductive output exhibited in the inshore region due to its patchy nature. While the 'region-specific pairing' method treated the inshore site as a single well-mixed region, the 'site-specific pairing' method assumed that the inshore region consisted of 3 patch reefs and assigned inshore settlers randomly to 1 of 3 sites $\left(\mathrm{I}_{1}, \mathrm{I}_{2}\right.$ or $\left.\mathrm{I}_{3}\right)$ with equal probability $(0.33)$. Thus, there is no difference in reproductive output in the offshore region between the 'regionspecific pairing' and 'site-specific pairing' scenarios.

Under the 'no pairing' scenario, reproductive output (i.e. the number of eggs produced) was estimated for each female after every molt, based on her post-molt size $\left(L_{\mathrm{f}}\right)$ and the relationship between female size and the number of eggs produced $\left(N_{\mathrm{e}}\right)$ (Eq. 1).

Under the 'region-specific' and 'site-specific' pairing scenarios, females reproduced only if there was a mature male in the same region or site, respectively, at the same time. Under both these scenarios, reproductive output was estimated for each reproductive event as above.

Under all 3 scenarios, total reproductive output was then estimated as the sum of all eggs produced in a particular region. Average total reproductive output was estimated among the 10 model simulations for each region under each of the 3 scenarios. Finally, to estimate source-sink potential, we estimated the ratio of larvae produced (i.e. number of eggs) in that region to the initial number of settlers to each region under each of the 3 scenarios.

\section{MODELING EXERCISES: RESULTS}

\section{Growth model}

The expected maximum size reached by shrimp in the 2 regions (in the absence of mortality) was fairly similar (54.4 mm TL vs. $51.5 \mathrm{~mm}$ TL for inshore versus offshore regions); however, the trajectories for the 2 regions differed substantially due to the variation in $j$ (the growth regression intercept) between regions, with shrimp in the inshore region predicted to reach particular sizes in approximately half the time required of those in the offshore region (Fig. 5a). For example, in the absence of mortality, inshore shrimp were expected to reach sexual maturity ( $30 \mathrm{~mm}$ TL) in less than $10 \mathrm{wk}$ (post-settlement), whereas those offshore were not expected reach maturity until ca. $20 \mathrm{wk}$.

\section{Demographic model}

When we combined the regional growth patterns with our size-specific rates of survivorship and repro- 


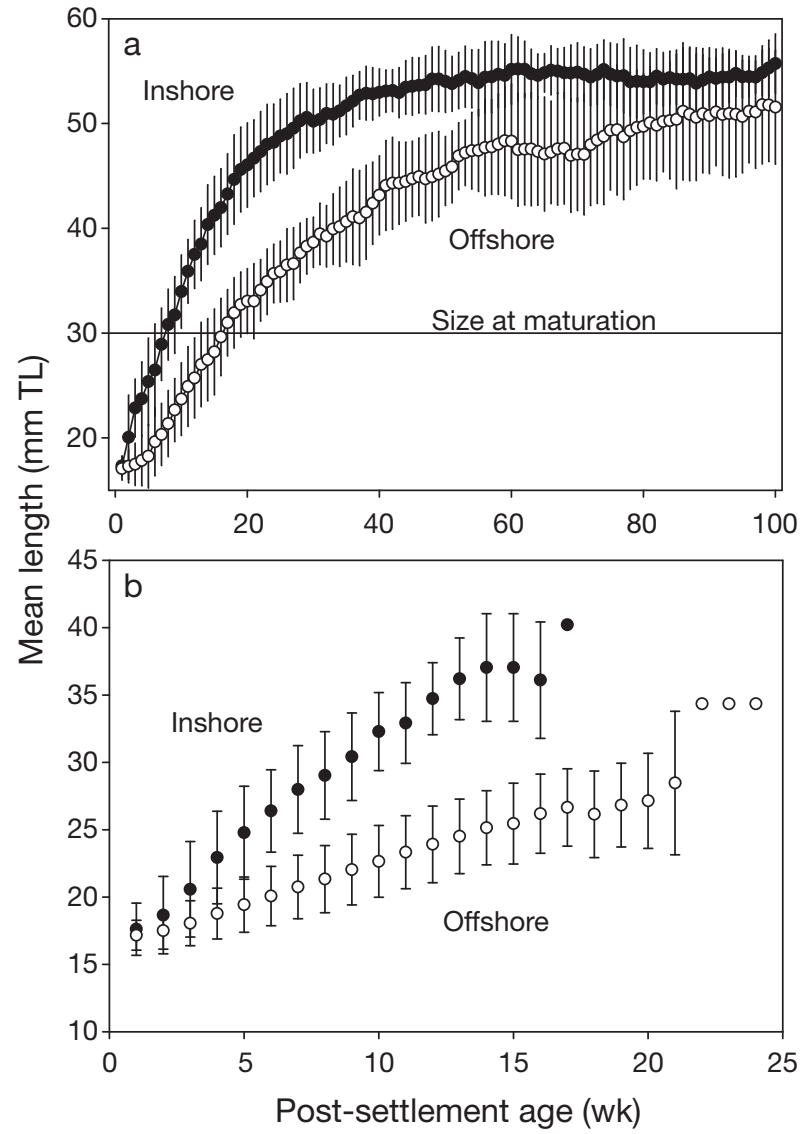

Fig. 5. Stenopus hispidus. Shrimp length against post-settlement age for inshore $(\bullet)$ and offshore (O) populations. (a) Mean \pm SD size at age from 20 simulations of the growth model (survival not incorporated) and (b) mean \pm SD size at age for the first run of demographic model. Points without SD estimates reflect those postsettlement ages that had only 1 surviving ind.

duction, shrimp in the inshore region were predicted to reach final sizes that were much larger than those reached by shrimp in the offshore region (e.g. Fig. 5b). In fact, across all 10 simulations, shrimp in the inshore region reached a maximum size of $43.4 \mathrm{~mm} \mathrm{TL}$, whereas shrimp from the offshore region reached a maximum size of $34.3 \mathrm{~mm}$ TL. The mean probability of survival \pm SE to maturity for the inshore region was $0.033 \pm 0.001$, while that for the offshore region was $0.0002 \pm<0.0001$. On average $\pm \mathrm{SE}$, it took surviving inshore shrimp $5.2 \pm 0.1 \mathrm{wk}$ to reach sexual maturity, whereas offshore shrimp took much longer, $11.6 \pm$ $0.4 \mathrm{wk}$.

Under the 'no pairing' scenario, there were 326 total reproductive events among the 10 simulations, 256 of which occurred in the inshore region. Mean total reproductive output (no. of eggs $\pm \mathrm{SE}$ ) for the inshore region was ca. 4.8 times larger than that offshore

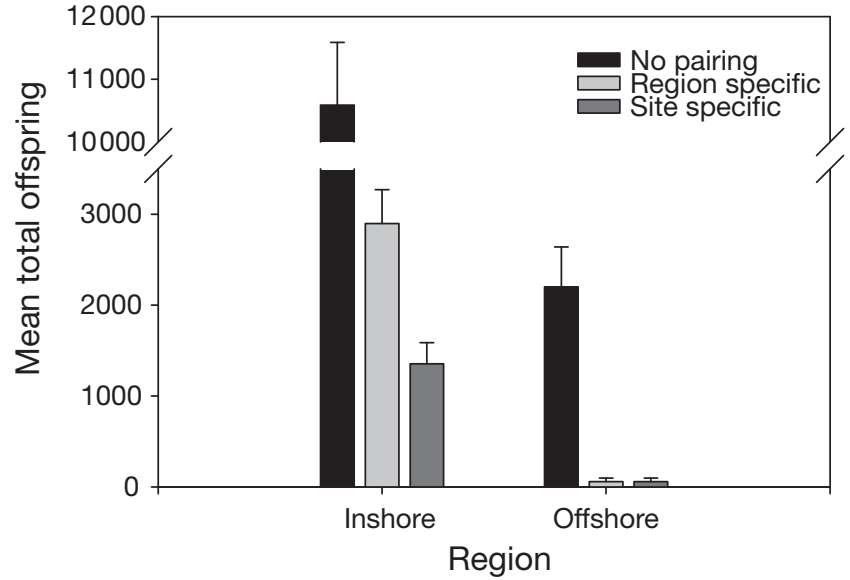

Fig. 6. Stenopus hispidus. Estimated mean total reproductive output \pm SE of inshore and offshore regions as predicted by the demographic model under the 3 reproduction scenarios: 'no pairing', 'region-specific pairing' and 'site-specific pairing'

(inshore: $10586 \pm$ 1000, offshore: $2201 \pm 439$; Fig. 6). The mean \pm SE ratio of larvae produced per larvae settled was $9.40 \pm 0.93$ in the inshore region, whereas that for the offshore region was $0.05 \pm 0.01$, indicating that the offshore region was a sink habitat.

Under the 'region-specific pairing' scenario, the total number of reproductive events decreased to 76 , with $97 \%$ occurring in the inshore region. Mean total reproductive output $\pm \mathrm{SE}$ in the inshore region decreased to $2897 \pm 373$ eggs, while that offshore decreased to $58.8 \pm 39.2$ eggs; Fig. 6 ). The mean \pm SE ratio of larvae produced per larvae settled was $2.59 \pm 0.36$ in the inshore region, whereas that for the offshore region was $0.001 \pm 0.001$. Also, under this scenario, the mean $\pm \mathrm{SE}$ proportion of sexually mature females remaining partner-less in the inshore region was $0.63 \pm 0.05$, whereas that for the offshore region was $0.94 \pm 0.04$. Finally, the mean \pm SE probability of survival to reproduction for females in the inshore region was $0.011 \pm 0.001$, while that for the offshore region was $<0.0001 \pm<0.0001$.

Under the 'site-specific pairing' scenario the total number of reproductive events decreased to 40 , with $95 \%$ occurring in the inshore region. Mean total reproductive output $\pm \mathrm{SE}$ for the inshore region decreased to $1354 \pm 233$ eggs (Fig. 6), while the mean \pm SE ratio of larvae produced per larvae settled decreased to $1.21 \pm$ 0.22 (recall that reproduction and production in the offshore region is the same as in the 'region-specific pairing' scenario). Finally, the mean \pm SE proportion of sexually mature females remaining partner-less in the inshore region increased to $0.79 \pm 0.04$, while the mean \pm SE probability of female survival to reproduction decreased to $0.006 \pm 0.001$. 


\section{DISCUSSION}

\section{Regional differences in demographic rates}

Our empirical results demonstrate spatial variation in key demographic rates and population attributes. For example, we found that settlement and abundance were greater, reproductive output was lower, body size was smaller and growth was lower in offshore compared to inshore reefs. Furthermore, when we incorporated these region-specific settlement, growth and mortality rates into a demographic model, we found a substantial difference in production between the inshore and offshore reefs that was similar to that measured in the empirical studies.

Spatial variation in growth in marine invertebrates and fishes has been attributed to many factors, including temperature (Wyban et al. 1995, reviewed in Hartnoll 2001), food availability (Kube et al. 1996, Hartnoll 2001) and depth (Srinivasan 2003). In the present study, the offshore region was deeper and cooler (by $1.2^{\circ} \mathrm{C}$ ) than the inshore region, although controlled growth studies are needed to determine whether this difference is sufficient to explain the regional growth patterns. Previous work with fishes has shown that survival is greater on isolated reefs than on more contiguous reefs (Overholtzer-McLeod 2004). Interestingly, we did not observe this pattern (i.e. inshore, fragmented sites yielded the same survival as offshore, contiguous reefs).

The mismatch between abundance and settlement (which were greater offshore) and production (i.e. growth and fecundity, which were greater inshore) is challenging. Greater settlement offshore may be due to current patterns that affect larval transport (Lee et al. 1992, Ogden 1997), larval habitat selection (Miron et al. 1999, Paula et al. 2001, Lecchini et al. 2005) or facilitative settlement (e.g. Sweatman 1985, Raimondi 1988, Sweatman \& St. John 1990, Wellington 1992, Lecchini et al. 2005, Donahue 2006). Unfortunately, we do not know what settlement cues Stenopus hispidus may be using, but any explanation must ultimately account for the observation that shrimp settle to regions where their growth and reproductive output is relatively low.

\section{Source-sink theory and marine management}

Based on our definition of sink habitats (i.e. those habitats that produce fewer offspring than they receive via larval settlement), the offshore region is a population sink, despite the high abundance of shrimp. Most of the individuals found in the offshore region were small and non-reproductive (Figs. 1 \& 6).
The offshore region is a sink because very few individuals mature. Abundance in this region remains high only because of the high settlement rate to the region. In contrast, the inshore region is more of a source but has low overall abundance because of low settlement. The inshore population consists of fewer but larger individuals that grow, survive and reproduce relatively well. Although the ratio of larvae produced per settler was high (range: 1.21 to 9.40) in the inshore region, we cannot clearly infer that the inshore region is a source because we do not know the survival of the larvae produced from this region. If the proportion of larvae that survive is greater than the reciprocal of the ratio of larvae produced per settler, then the inshore region functions as a source (i.e. if larval survival is between 0.11 and 0.83 ). Regardless of the magnitude of larval survival, the relative importance of inshore and offshore regions are markedly different, with the inshore region, where fewer shrimp occur, producing ca. 200 to 2600 times more larvae (per settler) than the offshore region.

The existence of population sinks for Stenopus hispidus is of particular concern due to its increasing popularity in the marine ornamental trade (i.e. the trade of marine fishes and invertebrates for marine aquaria). $S$. hispidus is just 1 of an estimated 2393 ornamental species harvested for the marine ornamental trade, a global fishery with an annual harvest of 20 to 24 million fishes, 11 to 12 million coral pieces and 9 to 10 million invertebrates (Wabnitz et al. 2003). Even with its global worth, the marine ornamental trade is still highly unregulated and is in need of information for the development of management strategies, as there have already been documented declines in local fish abundances and habitat quality where the trade is heaviest (Tissot \& Hallacher 1999).

Marine reserves have been proposed as potential tools for the sustainable management of marine ornamentals (Tissot \& Hallacher 1999). Source-sink dynamics must be considered in marine population management, and in particular with respect to the placement of marine reserves that are intended to be used as management tools (Crowder et al. 2000). So far, there are few studies that have documented the existence of population sinks in marine systems (but see Lipcius et al. 1997, Tupper \& Juanes 1999). Our results highlight the potential for densely populated sites to be sinks and suggest that demographic measures are key in locating areas for protection, for instance, with marine reserves (see also van Horne 1983, Crowder et al. 2000). Based on our results (although more data are clearly needed), it would seem prudent to allow harvest in offshore waters (where abundance is high but per capita production low), while protecting the inshore regions (where production is greater). 
Acknowledgements. We thank W. Lindberg for his assistance in analysis and interpretation of results, B. Bolker for his assistance with the model, J. Wilson, T. Adam, E. Hauck and L. Vigliola for their assistance in the field, the St. MaryOsenberg lab group and P. McHugh for critically reviewing an earlier version of this manuscript, and K. Clifton for providing facilities to B.R.C. during the writing of this manuscript. B. Ruttenberg and 3 anonymous reviewers provided helpful comments. We would also like to thank the Journal of Crustacean Biology for allowing us to publish an adaptation of a previously published figure from Chockley and St. Mary (2003). This work was funded by the University of Florida (Grinter Fellowship to B.R.C.), PADI Project AWARE (to B.R.C.), and National Sea Grant and NSF OCE-0242312 (to C.W.O., C.M.St.M. and B. Bolker).

\section{LITERATURE CITED}

Allison PD (1995) Survival analysis using the SAS System, a practical guide. SAS Publications, Cary, NC

Bailey KM, Houde ED (1989) Predation on eggs and larvae of marine fishes and the recruitment problem. Adv Mar Biol 25:1-67

Barbeau MA, Scheibling RE, Hatcher BG, Taylor LH, Hennigar AW (1994) Survival analysis of tethered juvenile sea scallops Placopecten magellancius in field experiments: effects of predators, scallop size and density, site and season. Mar Ecol Prog Ser 115:243-256

Caley MJ, Carr MH, Hixon MA, Hughes TP, Jones GP, Menge BA (1996) Recruitment and the local dynamics of open marine populations. Annu Rev Ecol Syst 27:477-500

Carr MH, Neigel JE, Estes JA, Andelman S, Warner RR, Largier JL (2003) Comparing marine and terrestrial ecosystems: implications for the design of coastal marine reserves. Ecol Appl 13:90-107

> Chen Y, Kennelly SJ (1999) Growth of spanner crabs Ranina ranina off the coast of Australia. Mar Freshw Res 50: 319-325

> Chockley BR, St. Mary CM (2003) Effects of body size on growth, survivorship and reproduction in the banded coral shrimp Stenopus hispidus. J Crustac Biol 23:836-848

Comeau M, Savoie F (2001) Growth increment and molt frequency of the American lobster Homarus americanus in the southwestern Gulf of St. Lawrence. J Crustac Biol 21:923-936

Cowen RK, Lwiza KMM, Sponaugle S, Paris CB, Olson DB (2000) Connectivity of marine populations: open or closed? Science 287:857-859

Crowder LB, Lyman SJ, Figueira WF, Priddy J (2000) Sourcesink population dynamics and the problem of siting marine reserves. Bull Mar Sci 66:799-820

> Donahue MJ (2006) Allee effects and conspecific cueing jointly lead to conspecific attraction. Oecologia 149:33-43

Fletcher DJ, Kötter I, Wunsch M, Yasir I (1995) Preliminary observations on the reproductive biology of ornamental cleaner prawns. Int Zoo Yrbk 34:73-77

Fogarty MJ (1999) Essential habitat, marine reserves and fishery management. Trends Ecol Evol 14:133-134

Gust N, Choat JH, Ackerman JL (2002) Demographic plasticity in tropical reef fishes. Mar Biol 140:1039-1051

> Hartnoll RG (2001) Growth in Crustacea-twenty years on. Hydrobiologia 449:111-122

> Hunt HL, Scheibling RE (1997) Role of early post-settlement mortality in recruitment of benthic marine invertebrates. Mar Ecol Prog Ser 155:269-301

Johnson VR Jr (1969) Behavior associated with pair formation in the banded coral shrimp Stenopus hispidus (Olivier). Pac Sci 23:40-50

Jones GP, Planes S, Thurrold SR (2005) Coral reef fish larvae settle close to home. Curr Biol 15:1314-1318

Kube J, Peters C, Powilleit M (1996) Spatial variation in growth of Macoma balthica and Mya arenaria (Mollusca, Bivalvia) in relation to environmental gradients in the Pomeranian Bay (Southern Baltic Sea). Arch Fish Mar Res 44:81-93

Lecchini D, Shima J, Banaigs B, Galzin R (2005) Larval sensory abilities and mechanisms of habitat selection of a coral reef fish during settlement. Oecologia 143:326-334

> Lee TN, Rooth C, Williams E, McGowan M, Szmant AF, Clarke ME (1992) Influence of Florida Current, gyres and wind-driven circulation on the transport of larvae and recruitment in the Florida Keys coral reefs. Cont Shelf Res 12:971-1002

> Leggett WC, Deblois E (1994) Recruitment of marine fishes: is it regulated by starvation and predation in the egg and larval stages. Neth J Sea Res 32:119-134

Limbaugh C, Pederson H, Chance FA Jr (1961) Shrimps that clean fishes. Bull Mar Sci Gulf Caribb 11:238-257

> Lipcius RN, Stockhausen WT, Eggleston DB, Marshall LS Jr, Hickey B (1997) Hydrodynamic decoupling of recruitment, habitat quality and adult abundance in the Caribbean spiny lobster: Source-sink dynamics? Mar Freshw Res 48:807-815

Miller TJ, Crowder LB, Rice JA, Marschall EA (1988) Larval size and recruitment mechanisms in fishes: toward a conceptual framework. Can J Fish Aquat Sci 45:1657-1670

Minchinton TE, Scheibling RE (1991) The influence of larval supply and settlement on the population structure of barnacles. Ecology 72:1867-1879

> Miron G, Boudreau B, Bourget E (1999) Intertidal barnacle distribution: a case study using multiple working hypotheses. Mar Ecol Prog Ser 189:205-219

Ogden JC (1997) Marine managers look upstream for connections. Science 278:1414-1415

Ólafsson EB, Peterson CH, Ambrose WG Jr (1994) Does recruitment limitation structure populations and communities of macro-invertebrates in marine soft sediments: the relative significance of pre- and post-settlement processes. Oceanogr Mar Biol Annu Rev 32:65-109

Overholtzer-McLeod KL (2004) Variance in reef spatial structure masks density dependence in coral-reef fish populations on natural versus artificial reefs. Mar Ecol Prog Ser 276:269-280

> Paula J, Dray T, Queiroga H (2001) Interaction of offshore and inshore processes controlling settlement of brachyuran megalopae in Saco mangrove creek, Inhaca Island (South Mozambique). Mar Ecol Prog Ser 215:251-260

> Pulliam HR (1988) Sources, sinks and population regulation. Am Nat 132:652-661

> Raimondi PT (1988) Settlement cues and determination of the vertical limit of an intertidal barnacle. Ecology 69:400-407

Roberts CM (1998) Sources, sinks and the design of marine reserve networks. Fisheries 23:16-19

Rochette R, Dill LM (2000) Mortality, behavior and the effects of predators on the intertidal distribution of littorinid gastropods. J Exp Mar Biol Ecol 253:165-191

> Ruttenberg BI, Haupt AJ, Chiriboga AI, Warner RR (2005) Patterns, causes and consequences of regional variation in the ecology and life history of a reef fish. Oecologia 145:394-403

Srinivasan M (2003) Depth distributions of coral reef fishes: the influence of microhabitat structure, settlement and post-settlement processes. Oecologia 137:76-84 
Stolen CK (1964) An analysis of the behavior of the cleaning shrimp Stenopus hispidus. Master's thesis, University of Hawaii, Honolulu, HI

Swearer SE, Shima JS, Hellberg ME, Thorrold SR and others (2002) Evidence of self-recruitment in demersal marine populations. Bull Mar Sci 70:251-271

Sweatman HPA (1985) The influence of adults of some coral reef fishes on larval recruitment. Ecol Monogr 55:469-485

Sweatman HPA, St. John J (1990) Effects of selective settlement and of aggression by residents on distribution of young recruits of two tropical damselfishes. Mar Biol 105:247-252

Tissot BN, Hallacher LE (1999) Impact of aquarium collectors on coral reef fishes in Kona, Hawaii. Final Report to the Division of Aquatic Resources, Honolulu, HI

Tremblay MJ, Eagles MD (1997) Molt timing and growth of the lobster Homarus americanus off northeastern Cape Brenton Island, Nova Scotia. J Shellfish Res 16:383-394

Tupper M, Juanes F (1999) Effects of a marine reserve on recruitment of grunts (Pisces: Haemulidae) at Barbados, West Indies. Mar Biol 55:53-63

van Horne B (1983) Density as a misleading indicator of habi-

Initial editorial responsibility: Howard Browman, Storebø,

Norway (until November 5, 2007); Final editorial responsibility: Matthias Seaman, Oldendorf/Luhe, Germany tat quality. J Wildl Manag 47:893-901

Wabnitz C, Taylor M, Green E, Razak T (2003) From oceans to the aquarium. UNEP-WCMC, Cambridge

Warner RR, Swearer SE, Casselle JE (2000) Larval accumulation and retention: implications for the design of marine reserves and essential fish habitat. Bull Mar Sci 66: 821-830

Wellington GM (1992) Habitat selection and juvenile persistence control the distribution of two closely related Caribbean damselfishes. Oecologia 90:500-508

Werner EE, Gilliam JF, Hall DJ, Mittelbach GG (1983) An experimental test of the effects of predation risk on habitat use in fish. Ecology 64:1540-1548

Wyban J, Walsh WA, Godin DM (1995) Temperature effects on growth, feeding rate and feed conversion of the Pacific white shrimp Penaeus vannamei. Aquaculture 138: $267-279$

Young F (1979) Spawning and rearing of the banded coral shrimp. Freshw Mar Aquar Mag 2:16-17

Zhang D, Lin J, Creswell RL (1998) Mating behavior and spawning of the banded coral shrimp Stenopus hispidus in the laboratory. J Crustac Biol 18:511-518

Submitted: July 25, 2007; Accepted: January 11, 2008

Proofs received from author(s): May 2, 2008 